\title{
Study of the Relationship between Vocal Music Works and Vocal Music Performance
}

\author{
Chuanzhi Zhong
}

Department of music, Nanchang Normal University

Keywords: Vocal music works; Vocal music performance; Dialectical unification relations

\begin{abstract}
The vocal music works and vocal music performance have developed into two attractive branches of vocal music art gradually from an integral whole. The dialectical unification relations between them are the steady stream of power for the development of vocal music art. This paper studies the relationship between vocal music works and vocal music performance from art, culture education and philosophy, and then clarifies the respective characteristics and dialectical unification relations of them to promote them develop rapidly towards the benign track where they promote each other.
\end{abstract}

\section{Introduction}

The development of music art is becoming more and more specialization and the division of work for the various factors in the music is more and more elaborated. And composers complete the music composition by writing a spectrum after the invention of notation which separates the composition as independent creative activities from the composers. Therefore, the vocal music works and vocal music performance are separating from each other and becoming two music courses with natural inner link and their respective independence. Meanwhile, both of them have experienced complex and tortuous development process with its own characteristics respectively. In history, our country's vocal music art has accumulated vast vocal music works, has created unique singing techniques and has brought up countless creators and singer people loved.

As a pair of inseparable unity, the vocal music works and vocal music performance are developing together in the blend and promotion relationship between each other. The increasing of vocal music works improves the technical requirements of vocal music and provides the prerequisite to the progress of vocal music performance at the same time. Vocal music performance is the carrier of value realization for the enrichment and development of vocal music works and the creation of vocal music works is the basis and motive power for the improvement of vocal music performance. Especially in the contemporary, there are a lot of examples in which the two art forms mingled with each other.

Through the analysis of vocal music works and vocal music performance along the relation theory from phenomenon to essence from art, culture education and philosophy, this paper makes further study for the deep relations of vocal music works and vocal music performance to avoid staying on the understanding of the single relationship between them isolated. So people can make a deep comprehensive and correct positioning for vocal music works and vocal music performance, that is the relationship the two art forms being the basis of artistic creation, the basis of knowledge transfer 
and the basis of promoting the development of dialectical unification of each other to promote them develop rapidly towards the benign track where they promote each other.

There is a highly generalization of correct positioning and discuss of the relationship between the vocal music works and vocal music performance based on the methodology, and there are deduction and reasoning from different theory view angles, such as art, culture education and philosophy in this paper to provide the correct theory basis for interpretation of vocal music works and correct understanding of second creation for many vocal music learners. This paper is not only the statement of theory, but also the association of the vocal music works creation and performance and the development process of the vocal music art in China. In order to promote the relationship between the two art forms develop rapidly towards the benign track where they promote each other, this paper select the composers and representative singers to demonstrate the relationship between them in the aspects of different theories angle which is the innovation points of this paper precisely.

\section{The introduction of development and essential characteristic of the vocal music works}

In the history of vocal music art development both in the west and in China, the poetry is the main source of the generation of vocal music works. In ancient Greece, there is no independent music without poetry and no independent poetry without music. At that time, a singer also was a poet and a composer who song the epic and folklore mainly. This is good proof that can show us the vocal music works is the result of poetry. The Iliad and the Odyssey, the famous vocal music works of ancient Greece were also the poetry which were created and song by blind artists. There are also many such kind of examples in ancient China. Such as the first anthology of poetry in the history of China- The Book of Songs, the music collection of the spring and autumn period is a collection of songs which contains 305 selected songs based on the 3,000 poems collected by the government of Zhou Dynasty compiled by Confucius. In the ancient society, music, dance and poetry are the early forms of art which were the trinity at the beginning and were separated into independent art form gradually later. Therefore, people can say that the vocal music works mainly come from poems.

The vocal music works are not only literary works in music but also music works in literary. Music and literature language present to be a co-creation relationship on the basis of each other in the existing way of vocal music works and form an indivisible whole. In literary language, there contains the beautiful rhythm of music, and in music language, there is also penetrated by the rhythm, tone of literary language with inner beauty. The language art pays attention to the cadence of the tone and the length combination of the syllable which happens to have the same view with the aesthetic pursuit and the aesthetic principles of music. However, it is necessary to use the rolling speed of tone and rhythm and the change of the strength in order to make the best performance of literariness and emotional implication of the language for the singers. All the art forms with singing style which are performance by music, such as the lyrics of songs and the libretto of opera and drama, etc. contain the literariness of the vocal music works.

In narrow sense, the form of literary language in vocal music work mainly concentrates on the lyrics and the libretto. But in general terms, the recitation, narrator and saying lines narratively to the lyrics and the libretto also have the characteristics of the literary language. The lyrics have the typical characteristics of poetry and distinctive characteristics of music, and music can performance and deepen the ideological content of the lyrics by its unique artistic language to form an interdependent relationship with literary lyrics. A piece of good vocal music work is also a beautiful poem, a lyric article, a catchy prose whose lyrics can inspire and arouse the composer to complete 
the creation of the music language under the guide of the beautiful literary language. In vocal music works, "the music language mainly refers to the composition of musical sound melody and various means and rules as a sum of music performance method based on the music tone or melody. Beautiful literary language requires beautiful music language." The creation pursuit and aesthetic standards of vocal music works are the harmonious and unified of the lyrics and tone. So people can say that one of the basic characteristics of vocal music works is the organic unification between the music language and the literary language.

\section{The introduction of development and essential characteristic of the vocal music performance}

The vocal music art has a long history of in China. In the long history of the development of Chinese music art, there is the origin of vocal music art. The development of vocal music performance in China is also in the turns and twists to go forward. This view that music originates from labor shows to people the origin of music. Labor creates human beings and also creates the art of music. In ancient China, poetry, music and dance are combined with each other which all originate from labor. Similarly, vocal music performance also originates from labor which can be shown by the content of many of the vocal music works in the primitive society period, such as Play Songs created in the period of Yellow Emperor.

"Artistic singing art is an art and also a science which reflects the strong artistic or creativeness when understands and performs the ideological content and music theme contains in the songs, creates the artistic conception of songs and holds and expresses the language rhythm and style. At the same time, artistic singing art reflects strict scientific when masters singing skills, such as voice, empathy, intonation and rhythm." Therefore, vocal music singing is a kind of form both reflects "art" and "technology". The technical skills of vocal music include the ability to sing various songs and the good ability of mind control trained in accordance with the certain scientific laws. The basic and fundamental of vocal music performance are the ability to sing. After mastering the basic ways of singing, such as breathing and its adjustment, the united coordination of language and sound, the adjustment of the resonance and music reading, song processing, the vocal music singer can perform the complete vocal music works in front of the audience perfectly. For the singing performance, vocal skills are the important and indispensable foundation but not the only condition for the success of vocal music singing, and also not the goal. There is something much more important than skills-the artistic charm shown when singing the vocal music works. Without the artistic appeal, the performance will be lifeless just like a shell without the soul which can't receive the recognition from the audience.

Therefore, skills and artistic can be the perfect unity only when the vocal music skills service for the artistic expression. As an art, vocal music performance Comes from life and is higher than life. Bring people the beautiful treat and intoxication of art, deepen people's feeling to beauty and improve the people's aesthetic consciousness are the biggest tasks of it. The vocal music singers should be based on the scientific voice skills for the purpose of artistic expression when singing vocal music works. Excellent singing skills and artistic expression in place are the two aspects both of which are indispensable. Only in this way, high grade artistic images can be created which show the value of vocal music itself. The vocal music singers loved by the audience can always make the excellent vocal music singing skills and artistic expression to be a perfect unity instead of just showing off their singing skills. Therefore, their excellent performance not only brings the people the aesthetic pleasure, but also moves the audience and their heart by rich and deep spiritual connotation 
and emotional pouring. Every vocal music learner and the singer should clearly know the purpose and real meaning of singing when singing to avoid falling into the wrong region of "show off the skills".

\section{The fundamental basis of vocal music performance is the vocal music work}

Throughout the history of vocal music, whether in China or Europe, the vocal music performance is closely linked with the vocal music work. Long time ago, they were integrated. The improvisation was not only the characteristics of folk music, but also the creation means of professional musician. After the Renaissance, there appeared professional composers and performers gradually who still were in a closely relationship. The practice process of vocal music art includes three links: works creation, performance and appreciation. First of all, there should be a vocal music work for the related performance. The vocal music works are the basis which be attached by the vocal music performance and the singing skills are also subject to the development and rules of creative thinking of vocal music works. Try to imagine that if there is lack of vocal music works, even the unparalleled singers cannot show their skills and the audience are unable to enjoy the sweet music; if there are no vocal music works both easy and difficult as the basis of practice, The vocal music learners cannot improve their level of vocal music performance step by step.

"The feeling expression and the transition between each other will be very reasonable and natural for a well-written song when analyzes it both from the lyrics and tune." A good vocal music work will provide good show stage for the singer, and a vocal music work which conforms to the singer's vocal tone color and range can make a contestant get high marks. Vocal music singers who are careful when choosing music understand the importance of vocal music works deeply. It is impossible to get people's love and praise if the vocal music work is awful though the singer's professional and skilled. The singers can express the vocal music work with beautiful singing performance only by making sure the theme, appreciating the emotional tone which the work need to express, analyzing the pausing and syntax between the lyrics and melody, understanding the era background of the song and other related knowledge when he gets the work.

\section{The important channel to make the vocal music works vividly and full of vitality is vocal music performance}

"Music performance is a kind of creative behavior which can give the music works with living life. Strictly speaking, the musical thoughts are taken the soul as lifeless musical notation when they are recorded by the composer in the form of music score. Music performance can make the music works regain life by changing the music score into flesh and blood and living music. If there is no music performance, music works only exists in the form of music score forever instead of being the real music." All the music art is a kind of performing art which needs to be represented through certain media. The music works which are appreciated by the audience are composed of two parts both of which are indispensable: the creation of the composer which means first creation; the performance of performers which means recreation. The play and expression of the connotation, meaning and emotion of the excellent vocal music works themselves need the actively cooperation and excellent performance of the singers. Pure traditional vocal music works are not able to convey the feelings and thoughts to people directly. Although the vocal music works in music score form contain the emotional, aesthetic and social experience of the creator, they still can't record of the 
delicate changes of human feeling's movement accurately no matter how detailed they are for the reason that it is difficult to show the intent of the creator fully just by the symbol. There are some potential factors to be excavated, supplemented and enriched and then conveyed to the audience which can provide a broad heaven and earth for vocal music performance. For the audience, the outstanding vocal music works are just lifeless and meaningless music score if there are no vocal music singing and performing. Therefore, vocal music singing can make the vocal music works vividly and also as the important way to conversion from vocal music works to the audio and visual form.

\section{The vocal music works and the vocal music performance are the cultural carrier of each other}

Culture is the sum of material wealth and spiritual wealth created by the human which includes language, literature, art and the spiritual wealth in all ideologies. As a special form of culture, the essence of vocal music art actually is also culture. Both the vocal music works and singing convey a kind of unique culture and a kind of national culture to the people. The cultures in Chinese and in the western are very different from each other which led to the differences of music art and vocal music art between China and the western and the differences of the cultural knowledge they convey to the people. As the treasures created by all nationalities in China in the history of the cultural and artistic and the comprehensive condensation and reflection of history and culture, psychological characteristics, way of thinking and expression, aesthetic temperament and interest owned by all nationalities in China about the vocal music art, Chinese national vocal music art contains the art crystallization of the ancient culture for thousands of years in China. Due to the differences of regional style, aesthetic habits, humanities knowledge, etc., there are differences between the vocal music art in Western Europe and China for their personality characteristics and the cultural information conveyed to people are distinguished, too.

If there are no cultural deposits in vocal music works and vocal music performance, the process of popularization and transmission will be general; if both of them aren't the carrier for each other, the communication with the audience must be superficial. The vocal music works and vocal music performance can obtain good results and reaction and meet the aesthetic needs of audience only in the minute that the cultural knowledge in unity expressed by both. Of course, the single cultural aesthetic idea has been replaced by the diverse aesthetic demand with the development of social progress, economic globalization and the resulting cultural diversity which means that people want to appreciate the unity of vocal music works and performance mingled in various cultural spirits.

\section{The vocal music works and the vocal music performance are the developing basis and dialectical unification of each other}

Belinsky pointed out that: "the content without form or the form without content are not existed." The content and form is a pair of philosophical category about the relationship between the internal factors and external expression of things. As one of the aesthetic objects, vocal music art is also the unity of content and form. The relationship between content and form of art is mutual, inseparable, dialectical and unified. In the development of vocal music art in China, the vocal music works and performance is also a pair of inseparable category. From the view of philosophy, the specific deduction of the content and form of vocal music art is: the vocal music work is the content, that is the "origin"; the vocal music performance is the form, that is expressive form of "origin". Therefore, 
based on the dialectical relationship between content and form in philosophical category, the relationship between the vocal music work and vocal music performance can be positioned that: in vocal music art, the vocal music work is the content and the essence which plays a leading and crucial role, and vocal music performance is the form and the expression of the content which services for the vocal music work with the development of it. In the meantime, vocal music performance can make positive influence to the vocal music works instead of being passive. The dialectical unification relations between the vocal music work and vocal music performance which is Interdependent and mutually reinforcing is the powerful force to improve the development of vocal music art.

The innovation and development of the vocal music work promote the development of the vocal music art in China. Good singing skills must be shown by appropriate vocal music works and the excellent vocal music works should be performed by the right sound which are complement each other and in an indivisible dialectical relationship. Firstly, the composer creates vocal music work, and then the singer sings the work according to the understanding and interpretation to it which is easy to learn that the work is the origin and the performance is the recreation. Therefore, people can say that the development of vocal music works can promote the improvement of vocal music performance and ask more for the singer's skills.

Judging from the development course of vocal music career in China, the progress and prosperity of vocal music skills goes hand in hand with the plethora of vocal music works. In the footsteps of the ages, it is easy to find the increase and progress of the vocal music works. And in the progress, people can say that the requirements of vocal music skills are improving constantly. From the table represents the creation time and range of the typical Chinese vocal music works showed below, we can say the inexorable trend that the requirements to the vocal music skills are enhanced with the development of the vocal music works more clearly and specifically.

The singers convey the thought of the composer to the audience by the skills of the vocal music performance. So the ability and skills of singing should also be consistent with the request of the ages. The inheritance of Chinese national vocal music culture not only shows the aesthetic pursuit and aesthetic changes of various periods and various stages, but also sets the brand of the ages for the singers. Only from the two ways of the application of singing skills and singing ability and the vocal music performance, the progress of the singers generation after generation is obvious. A group of singers, such as Wang Kun, Li Bo established the "operas and songs singing method" preliminary using the virtues and strengths of the opera singing for reference on the basis of folk singing. In the creation period, they obtained very precious experience in art, but also left some unsolved problems, such as the skill problems: shouting the high pitch, tight throat. During the period of the founding of our country, the famous singer Guo Lanying created and developed her own singing style gradually after inheriting the art experiences of Wang Kun and other predecessors. Her voice was more suitable for the new style of opera performance for its richer expressive force and more exquisite emotional expression. In 1945, Guo Lanying played the role of Xier incisively and vividly in the opera White Haired Girl which caused a sensation throughout the country. But singing with the "real voice" is an important factor which restricts the development of the singing skills and the key point which affects the breakthrough of skills in treble. 


\section{Conclusions}

Throughout the history of the vocal music art development, the vocal music works and the vocal music performance are always blend and relying on each other whose synchronization coincidence is the root cause of the development and progress of the vocal music art. No matter from the angle of art, cultural education, or philosophical, the essence of the relations between the vocal music works and the vocal music performance is the expression in the art, the reflection in vocal music culture of the law of the unity of opposites in philosophy which is also the core and basis of the relations between them.

In the syndrome differentiation theory of philosophical category, contradiction which means the unity of opposites is the root cause of things sports development and the source and driving force of the development of the things. So the unity of opposites of the vocal music works and the vocal music performance in different levels and angles is the source of development and progress of the vocal music art. The vocal music works and the vocal music performance constitute the concrete connotation of vocal music art as a whole and condition each other which exist and develop in the interdependent unity. For example, in the field of art, the "first creation" and the "recreation" are the basis for artistic creation; in the field of culture and education, the vocal music works and the vocal music performance are the carrier and effective way to convey the cultural knowledge for each other; in the field of philosophy, both of them are the power to promote the development of each other. The contrariety of them is pushing the changes of the both parties' force together and achieving consistency finally to promote the development of the vocal music art. For example, the diversification of vocal music styles requires the diversification of vocal music singing style inevitably; the rapid development of the vocal music skills have challenged the expressive force of vocal music works which needs the composers create the vocal music works that can fully demonstrate the singers' skills and the singing ability; the delivery of the vocal music works demands to improve the quality of vocal music singers to adapt itself, etc.

\section{References}

[1] Lv Ji and others, Music, Dance Volume of Encyclopedia of China.[M]. Beijing: The Encyclopedia of China Publishing House, September, 2004

[2] Han Xunguo, Han Xiaotong, Course in Singing. [M]. Wuhan: Wuhan University Press, September, 2006

[3] Guo Jianmin, Vocal Music Culture.[M]. Shanghai: Shanghai Music Publishing House, August,2007

[4] Wang Hongbo, Li Jianqun, Treatise on Philosophy.[M]. Xi'an: Xi'an Jiaotong University Press, January,2002

[5] Lin Dehong, General Philosophy.[M」. Nanjing: Nanjing University Press, January, 1997

[6] Yang Chengyin, Introduction to Aesthetic Category.[M]. Zhejiang: Zhejiang Academy of Fine Arts Press, March,1991

[7] Ji Shuihe, The Essentials of Aesthetic Theory.[M]. Wuhan: Wuhan University Press, May, 1992

[8] Tian Shaoliu, Liu Jialiang, Introduction to Art.[M]. Jinan: Qilu Publishing House, October, 2004

[9] Xu Zhimeng, Qin Yi, Wu Renyuan, Art and esthetic.[M]. Beijing: Mechanical Industry Press, May, 1993 
[10]Zhang Qian, Wang Ciyi, Music Aesthetics Basis.[M]. Beijing: People's Music Publishing House, May, 1992

[11]Luo Xianjun, Li Binsun, Xu Lang, The Collection of Chinese Music Works1-4.[M]. Beijing: People's Music Publishing House, May, 2001 